\title{
FPGA implementation of adaptive sliding mode control and genetically optimized PID control for fractional-order induction motor system with uncertain load
}

\author{
Karthikeyan Rajagopa ${ }^{1 *}$ (D) Guessas Laarem², Anitha Karthikeyan ${ }^{1}$ and Ashokkumar Srinivasan ${ }^{1}$
}

\section{"Correspondence:}

rkarthiekeyan@gmail.com

${ }^{1}$ Centre for Non-Linear Dynamics,

Defense University, Bishoftu,

Ethiopia

Full list of author information is

available at the end of the article

\section{Springer}

\begin{abstract}
In this paper, we investigate the control of 4-D nonautonomous fractional-order uncertain model of a PI speed-regulated current-driven induction motor (FOIM) using a fractional-order adaptive sliding mode controller (FOASMC). First, we derive a dimensionless fractional-order model of the induction motor from the well-known integer -model of the induction motor. Various dynamic properties of the fractional-order induction motor, such as stability of the equilibrium points, Lyapunov exponents, bifurcation, and bicoherence, are investigated. An adaptive controller is derived to suppress the chaotic oscillations of the fractional-order model of the induction motor. Numerical simulations of the adaptive chaos suppression methodology are depicted for the fractional-order uncertain model of the induction motor to validate the analytical results of this work. A genetically optimized fractional-order PID (FOPID) controller is also derived to stabilize the states of the FOIM system. FPGA implementation of the proposed FOASMC is also presented to show that the proposed controller is hardware realizable.
\end{abstract}

MSC: 34H10; 26A33; 34A08

Keywords: induction motor; chaos suppression; fractional order; Lyapunov stability; FPGA

\section{Introduction}

Electric motors consume approximately $65 \%$ to $70 \%$ of the electric energy [1]. Industry and household applications depend mostly on alternating current $(\mathrm{AC})$ electric motors. It is well known that $90 \%$ of these AC electric motors are induction motors. A majority of modern devices use induction motors, and the motor drive operates under various loads. A rapid change of load allows one to increase the productivity of the motor, but at the same time it may lead to various undesirable effects such as motor stopping, vibration, damage, or failure of the device itself. So the investigation of induction motor operation under sudden changes of load becomes a critical issue. Mathematical models of induction motor with various rotors and analysis of their stability and oscillations were studied by Solovyeva [2]. The control of an induction motor is a very complicated research problem due to highly nonlinear characteristics, coupling, and time varying dynamics [3].

(c) The Author(s) 2017. This article is distributed under the terms of the Creative Commons Attribution 4.0 International License (http://creativecommons.org/licenses/by/4.0/), which permits unrestricted use, distribution, and reproduction in any medium, provided you give appropriate credit to the original author(s) and the source, provide a link to the Creative Commons license, and indicate if changes were made. 
Fractional-order calculus developed from ordinary calculus is a generalization of the integration and differentiation to the noninteger-(fractional-)order generalization operator ${ }_{a} D_{t}^{q}$ in which $a$ and $t$ are limits and $q$ is the order of the operator. This notation is used for both the fractional derivatives and fractional integrals in a single expression [4]. Two general fractional-order integral/differential operations are commonly discussed, viz. Caputo and Riemann-Liouville (R-L) fractional operators. Physically, the R-L fractional operator has an initial value problem [5]. Thus, the Caputo fractional operator is more practical than the R-L fractional one.

The benefits of using fractional-order models of real dynamical objects and processes of applications appear in various fields of science and technology [6]. The synchronization of chaotic systems has been implemented in many engineering applications with integerorder derivatives [7-11]. However, only a few works have been reported on the synchronization of fractional-order chaotic systems, since the proof of stability of fractional-order systems is more complex than the chaotic systems with integer-order derivatives [6]. Synchronization of chaotic systems deals with asymptotically synchronizing the state trajectories of a pair of chaotic systems called the master and slave systems. Many control techniques have been developed for the chaos synchronization of integer-order chaotic systems such as active control [12-16], adaptive control [17-21], sliding mode control [2225], backstepping control [26-28], fuzzy control [29, 30], and so on.

A bifurcation diagram shows the long-term qualitative changes (equilibria or periodic orbits) of a system as a function of a bifurcation parameters of the system. The complete dynamics of the system with variation of parameters can be studied with the help of bifurcation diagrams [31, 32]. Nonlinear dynamical system undergoes abrupt qualitative changes when crossing bifurcation points [33]. For a more exhaustive qualitative analysis of a nonlinear dynamic system, it is compulsory to identify both singularities of the parameter plane and singularities of the phase plane [34,35].

The stability of fractional-order systems using Lyapunov stability theory has been investigated in the literature [36,37]. A fractional-order controller to stabilize the unstable fixed points of an unstable open-loop system was proposed by Tavazoei and Haeri [38]. A delayed feedback control (DFC) based on the act-and-wait concept for nonlinear dynamical systems was proposed by Konishi et al. [39], who reduce the dynamics of DFC systems to that of discrete-time systems.

With the LabVIEW simulation module, we can investigate the dynamic behavior of complex engineering systems. An experimental study of the fractional-order proportional derivative (FO-PD) controllers using LabVIEW was investigated by Jin et al. [40]. Digital implementation of a 3-D chaotic system with three quadratic nonlinearities using LabVIEW was studied by Vaidyanathan et al. [41]. The control and synchronization of an induction motor system was investigated by Chen et al. [42]. Fractional-order systems were investigated by many methods in the literature [43-47]. Many chaotic systems with hidden attractors were investigated by Jafari et al. [48-53]. Analysis of chaotic systems with multistability helps researchers in nonlinear controller design to modify the algorithms with reference to the parameter selections $[54,55]$. Asymptotic stability of Caputo fractional derivatives are recently investigated [56]. Some recent works discussed the fractional-order applications in financial models [57].

This paper is organized as follows. In Section 2, we derive a fractional-order model of the induction motor system $[3,42]$. In Section 3 , we investigate the dynamic properties of 
the fractional-order induction motor system (FOIMS). In Section 4, we derive fractionalorder controllers for suppressing the chaotic oscillations of the FOIMS. In Section 5, we derive the stability of the controllers, and Section 6 , we numerically check the results. In Section 6, we derive PID control [58] optimized by genetic optimization algorithm [5961]. In Section 7, we implement adaptive sliding mode controllers in FPGA [55] using Xilinx vivado tools to show that the controller is hardware realizable.

\section{Fractional-order current driven induction motor}

The nonlinear dynamical model of a current-driven induction motor system in a rotating reference frame is given by

$$
\begin{aligned}
& \dot{\phi}_{q r}=-\frac{R_{r}}{L_{r}} \phi_{q r}-\omega_{s t} \phi_{d r}+\frac{L_{m}}{L_{r}} R_{r} I_{q s}, \\
& \dot{\phi}_{d r}=-\frac{R_{r}}{L_{r}} \phi_{d r}-\omega_{s t} \phi_{q r}+\frac{L_{m}}{L_{r}} R_{r} I_{d s}, \\
& \dot{\omega}_{r}=-\frac{R_{\omega}}{J} \omega_{r}+\frac{1}{J}\left[\frac{3}{L} \frac{L_{m}}{L_{r}} \eta_{p}\left(i_{q s} \phi_{d r}-i_{d s} \phi_{q r}\right)-T_{L}\right],
\end{aligned}
$$

where $R_{r}$ is the rotor resistance, $L_{r}$ is the rotor self-inductance, $L_{m}$ is the rotating frame mutual inductance, $\eta_{p}$ is the number of pole pairs, $\omega_{s t}$ is the slip frequency, $J$ is the inertial coefficient, $T_{L}$ is the load, $\phi_{q r}$ and $\phi_{d r}$ are the quadratic and direct axis components, $\omega_{r}$ is the rotor angular speed, and $R_{\omega}$ is the rotating resistance.

Let us define $c_{1}=\frac{R_{r}}{L_{r}}, c_{2}=\frac{L_{m}}{L_{r}} R_{r}, c_{3}=\frac{R_{w}}{J}, c_{4}=\frac{1}{J}, c_{5}=\frac{3}{2} \frac{L_{m}}{L_{r}} \eta_{p}, u_{1}=\omega_{s t}, u_{2}=i_{d s}, u_{3}=i_{q s}$ and the new state variables as $x_{1}=\phi_{q r}, x_{2}=\phi_{d r}$. Let the PI speed control strategy be defined as

$$
\begin{aligned}
& u_{1}=\hat{c}_{1} \frac{u_{3}}{u_{2}}, \\
& u_{2}=u_{2}^{0}, \\
& u_{3}=k_{p}\left(\omega_{\mathrm{ref}}-\omega_{r}\right)+k_{i} \int_{0}^{t}\left(\omega_{\mathrm{ref}}(\tau)-\omega_{r}(\tau)\right) d \tau,
\end{aligned}
$$

where $\hat{c}_{1}$ is the estimate of $c_{1}, \omega_{\text {ref }}$ is the constant reference velocity, $u_{2}^{0}$ is the constant reference for the rotor flux magnitude, $k_{p}, k_{i}$ are the proportional and integral gains of the PI controller. Using (2) in (1) with the defined new states and coefficients, the dimensionless integer-order model of a PI speed-regulated current-driven induction motor [3, 42] is defined as

$$
\begin{aligned}
& \dot{x}_{1}=-c_{1} x_{1}+c_{2} x_{4}-\frac{k c_{1}}{u_{2}^{0}} x_{2} x_{4}, \\
& \dot{x}_{2}=-c_{1} x_{2}+c_{2} u_{2}^{0}+\frac{k c_{1}}{u_{2}^{0}} x_{1} x_{4}, \\
& \dot{x}_{3}=-c_{3} x_{3}-c_{4}\left[c_{5}\left(x_{2} x_{4}-x_{1} u_{2}^{0}\right)-T_{L}-\frac{c_{3}}{c_{4}} w_{\text {ref }}\right], \\
& \dot{x}_{4}=\left(k_{i}-k_{p} c_{3}\right) x_{3}-k_{p} c_{4}\left[c_{5}\left(x_{2} x_{4}-x_{1} u_{2}^{0}\right)-T_{L}-\frac{c_{3}}{c_{4}} w_{\text {ref }}\right] .
\end{aligned}
$$


System (3) undergoes chaotic behavior when the parameters take the following values:

$$
\begin{aligned}
& c_{1}=13.67 \mathrm{~s}^{-1}, \quad c_{2}=1.56 \mathrm{Hs}^{-1}, \quad c_{3}=0.59 \mathrm{~s}^{-1}, \\
& c_{4}=1176 \mathrm{Kg}^{-1} \mathrm{~m}^{-2}, \quad c_{5}=2.86, \quad u_{2}^{0}=4 \mathrm{~A}, \\
& k_{p}=0.001, \quad k_{i}=0.55, \quad k=3.15, \quad T_{L}=1.5, \quad w_{\mathrm{ref}}=181.1 \mathrm{rad} / \mathrm{s} .
\end{aligned}
$$

The fractional-order differential operator is a generalization of an integer-order differential operator. There are three commonly used definitions of the fractional-order differential operator, viz. Grunwald-Letnikov, Riemann-Liouville, and Caputo [45, 46]. However, in applications of fractional calculus in science and engineering, the Caputo derivative and Riemann-Liouville are mostly used. In the literature [40-51], mostly the Caputo derivative is preferred since the initial value of a fractional differential equation with $\mathrm{Ca}$ puto derivative is the same as that of an integer differential equation. Hence we derive the fractional-order model of PMSG from (1) with the Caputo fractional order definition, which is defined as

$$
D_{t}^{\alpha} f(t)=\frac{1}{\Gamma(1-\alpha)} \int_{t_{0}}^{t} \frac{\dot{f}(\tau)}{(t-\tau)^{\alpha}} d \tau
$$

where $\alpha$ is the order of the system, $t_{0}$ and $t$ are limits of the fractional-order equation, and $\dot{f}(t)$ is the first-order derivative of the function. For numerical calculations, equation (4) is modified as

$$
{ }_{(t-L)} D_{t}^{\alpha} f(t)=\lim _{h \rightarrow 0}\left\{h^{-\alpha} \sum_{j=0}^{N(t)} b_{j}(f(t-j h))\right\} .
$$

Theoretically, fractional-order differential equations use infinite memory. When we wish to numerically calculate or simulate fractional-order equations, we have to use finite-memory principle, where $L$ is the memory length, and $h$ is the time sampling as $N(t)=\min \left\{\left[\frac{t}{h}\right],\left[\frac{L}{h}\right]\right\}, b_{j}=\left(1-\frac{a+\alpha}{j}\right) b_{j-1}$.

Applying these fractional-order approximations of the derivatives in system (3), we obtain the fractional-order model of the chaotic induction motor given by the following $d y-$ namics:

$$
\begin{aligned}
& D_{t}^{q_{1}} x_{1}=-c_{1} x_{1}+c_{2} x_{4}-\frac{k c_{1}}{u_{2}^{0}} x_{2} x_{4}, \\
& D_{t}^{q_{2}} x_{2}=-c_{1} x_{2}+c_{2} u_{2}^{0}+\frac{k c_{1}}{u_{2}^{0}} x_{1} x_{4}, \\
& D_{t}^{q_{3}} x_{3}=-c_{3} x_{3}-c_{4}\left[c_{5}\left(x_{2} x_{4}-x_{1} u_{2}^{0}\right)-T_{L}-\frac{c_{3}}{c_{4}} w_{\text {ref }}\right], \\
& D_{t}^{q_{4}} x_{4}=\left(k_{i}-k_{p} c_{3}\right) x_{3}-k_{p} c_{4}\left[c_{5}\left(x_{2} x_{4}-x_{1} u_{2}^{0}\right)-T_{L}-\frac{c_{3}}{c_{4}} w_{\mathrm{ref}}\right],
\end{aligned}
$$

where $q_{1}, q_{2}, q_{3}, q_{4}$ are the fractional orders of the derivatives, and parameter values are taken as in the integer-order model.

System (6) is chaotic when the parameter values are taken as in (2) and the commensurate fractional orders are taken as

$$
q_{1}=0.9, \quad q_{2}=0.9, \quad q_{3}=0.9, \quad q_{4}=0.9 .
$$



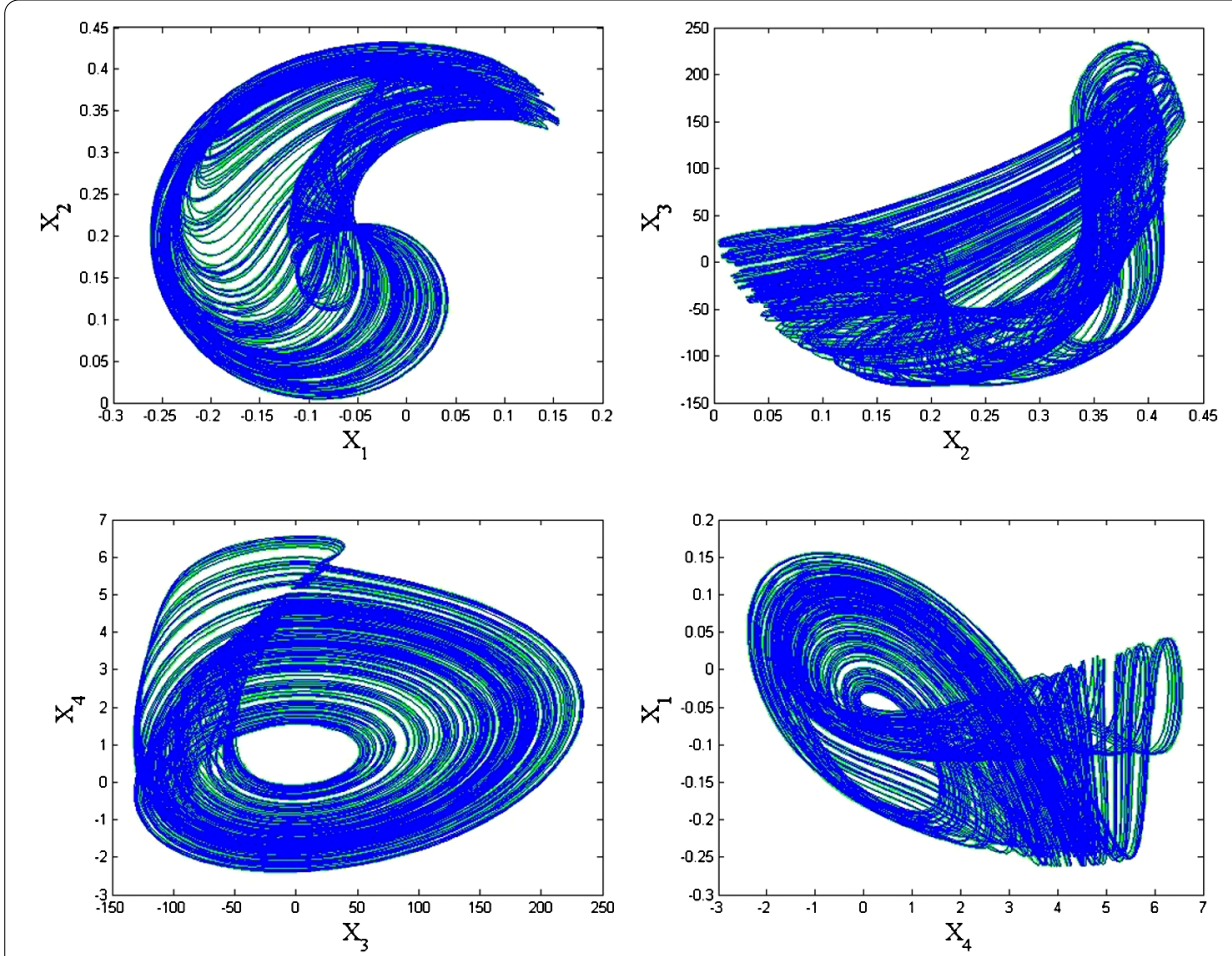

Figure 1 2-D state portraits of the fractional-order induction motor.

For numerical simulations, we take the initial conditions

$$
x_{1}=0, \quad x_{2}=0.4, \quad x_{3}=-200, \quad x_{4}=6 \text {. }
$$

Figure 1 shows the 2-D chaotic phase portraits of the fractional induction motor system (6) in $\left(x_{1}, x_{2}\right),\left(x_{2}, x_{3}\right),\left(x_{3}, x_{4}\right)$, and $\left(x_{4}, x_{1}\right)$ planes.

\section{Dynamical analysis of the fractional-order system}

In this section, we analyze the fractional-order induction motor system (6) for various properties of chaotic behavior like equilibrium points, Lyapunov exponents, bifurcation, and bicoherence.

\subsection{Equilibria points and Lyapunov exponents}

The equilibrium points of the induction motor system (6) can be found by solving the following system of nonlinear equations:

$$
\left\{\begin{array}{l}
0=-c_{1} x_{1}+c_{2} x_{4}-\frac{k c_{1}}{u_{2}^{0}} x_{2} x_{4}, \\
0=-c_{1} x_{2}+c_{2} u_{2}^{0}+\frac{k c_{1}}{u_{2}^{0}} x_{1} x_{4}, \\
0=-c_{3} x_{3}-c_{4}\left[c_{5}\left(x_{2} x_{4}-x_{1} u_{2}^{0}\right)-T_{L}-\frac{c_{3}}{c_{4}} w_{\mathrm{ref}}\right], \\
0=\left(k_{i}-k_{p} c_{3}\right) x_{3}-k_{p} c_{4}\left[c_{5}\left(x_{2} x_{4}-x_{1} u_{2}^{0}\right)-T_{L}-\frac{c_{3}}{c_{4}} w_{\mathrm{ref}}\right] .
\end{array}\right.
$$

The induction motor system (6) has a unique real equilibrium point

$$
E_{1}=[-0.017,0.455,0,0.304] .
$$




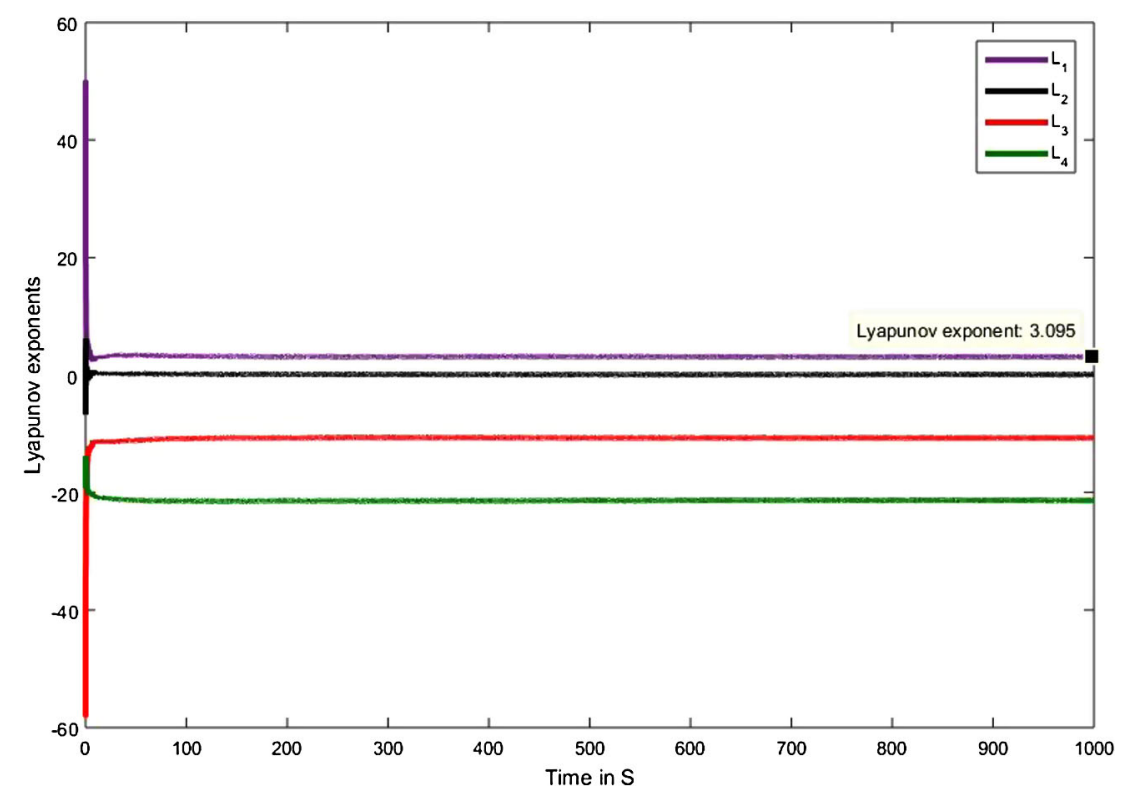

Figure 2 Lyapunov exponents of the fractional-order induction motor system.

The Jacobian matrix of the induction motor system (6) is calculated as

$$
J=\left[\begin{array}{cccc}
-c_{1} & \frac{-k c_{1}}{u_{2}^{0}} x_{4} & 0 & c_{2}-\frac{k c_{1}}{u_{2}^{0}} x_{2} \\
\frac{k c_{1}}{u_{2}^{0}} x_{4} & -c_{1} & 0 & \frac{k c_{1}}{u_{2}^{0}} x_{1} \\
c_{4} c_{5} u_{2}^{0} & -c_{4} c_{5} x_{4} & -c_{3} & -c_{4} c_{5} x_{2} \\
k_{p} c_{4} u_{2}^{0} & -k_{p} c_{4} c_{5} x_{4} & k_{i}-k_{p} c_{3} & -k_{p} c_{4} c_{5} x_{2}
\end{array}\right] .
$$

The initial conditions are chosen as in (8), and the commensurate fractional orders of the system are taken to be 0.9 . The eigenvalues of system (6) at $E_{1}$ are $\lambda_{1,2}=$ $1.303 \pm 29.080 i, \lambda_{3}=-18.26$, and $\lambda_{4}=-13.82$. System (6) shows a dissipative structure as $\operatorname{div} V=\sum_{i=1}^{4} \frac{\partial \dot{x}_{i}}{\partial x_{i}}<0$. The Lyapunov exponents of the fractional-order system (6) are $L_{1}=3.095, L_{2}=0, L_{3}=-11.029019$, and $L_{4}=-21.079318$. Figure 2 shows the Lyapunov exponents of the fractional-order induction motor system (6).

\subsection{Bifurcation and bicoherence}

By fixing all the other parameters, $T_{L}$ is varied, and the behavior of the fractional-order induction motor system (6) is investigated. The bifurcation plot for various states versus load $T_{L}$ is given by Figures 3 and 4 . Generally speaking, when the greatest Lyapunov exponent of the system is larger than zero and the points in the corresponding bifurcation diagram are dense, a chaotic attractor is found to exist in this system. Therefore, from the Lyapunov exponents and bifurcation diagrams in these figures we conclude that chaos exists in the fractional-order system (6) when selecting a certain range of parameters. Next, the individual state responses are studied in detail by varying the parameters.

The second important bifurcation analysis is with the fractional order $q$, and to investigate this, we derive the bifurcation of FOIM with commensurate fractional order as shown in Figures 5 and 6 . As can be seen from the figures, the FOIM system shows routine period doubling route to chaos and shows chaotic oscillations for $q \geq 0.975$. 
Figure 3 Bifurcation of state $X_{1}$ versus $T_{L}$.

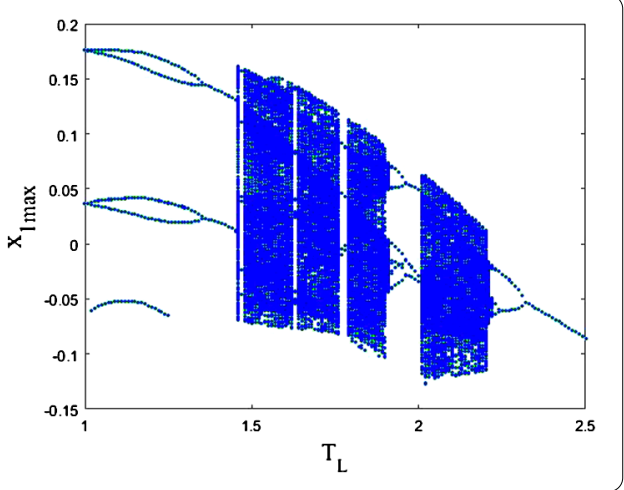

Figure 4 Bifurcation of state $X_{2}$ versus $T_{L}$.

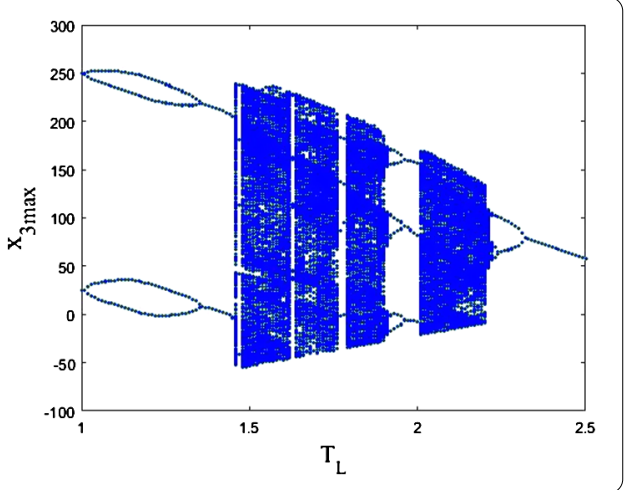

Figure 5 Bifurcation of state $X_{1}$ versus $q$.

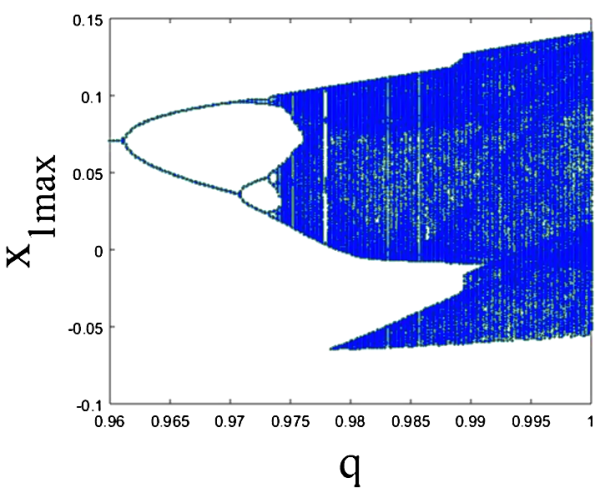

The bicoherence or the normalized bispectrum is a measure of the amount of phase coupling that occurs in a signal or between two signals [62,63]. Both bicoherence and bispectrum are used to find the influence of a nonlinear system on the joint probability distribution of the system input. Phase coupling is the estimate of the proportion of energy in every possible pair of frequency components $f_{1}, f_{2}, f_{3}, \ldots, f_{n}$. Bicoherence analysis is able to detect coherent signals in extremely noisy data, provided that the coherency remains constant for sufficiently long times, since the noise contribution falls off rapidly with increasing $N$. The auto- and cross-bispectrum of a nonlinear system is presented by Pezeshki $[62,63]$. He derived the bispectrum with the Fourier coefficients

$$
B\left(\omega_{1}, \omega_{2}\right)=E\left[A\left(\omega_{1}\right) A\left(\omega_{2}\right) A^{*}\left(\omega_{1}+\omega_{2}\right)\right],
$$


Figure 6 Bifurcation of state $X_{4}$ versus $q$.
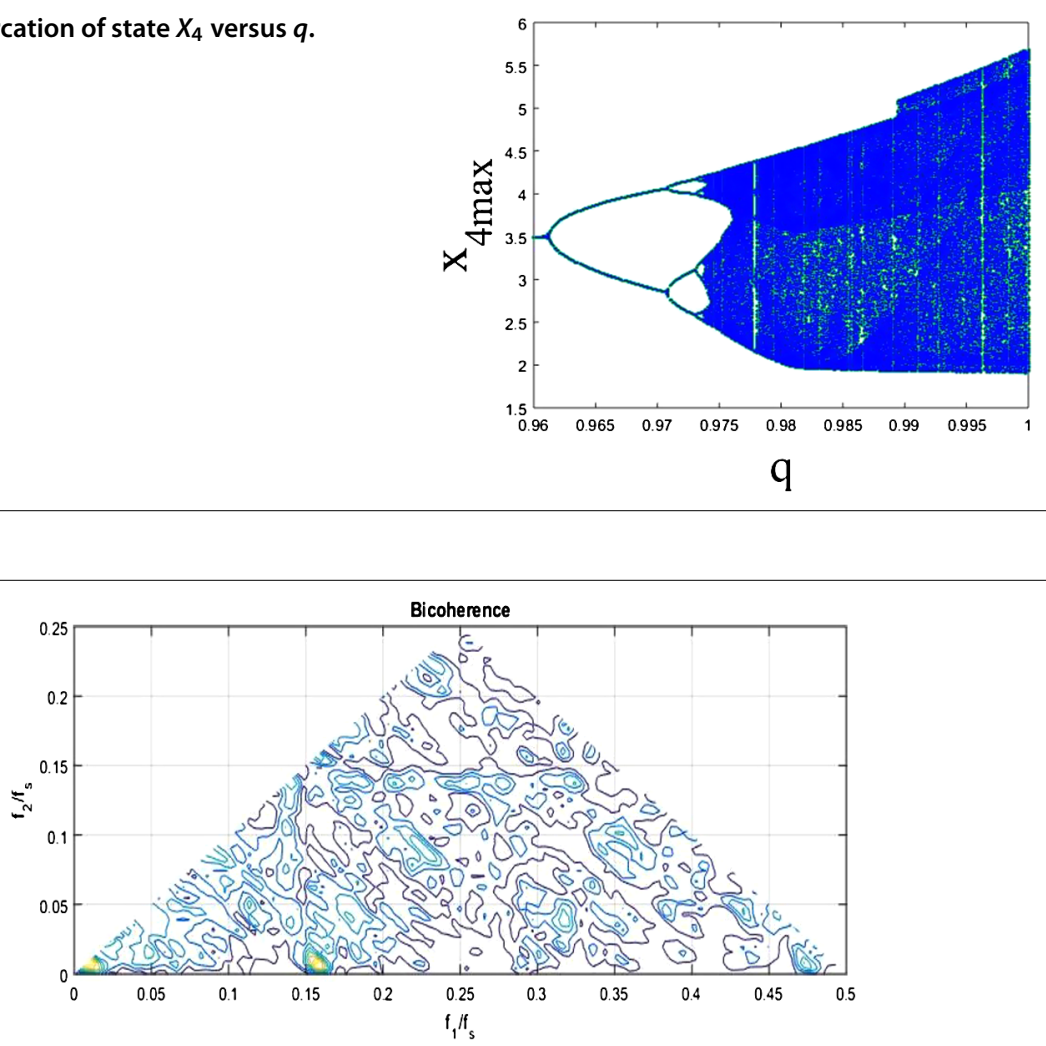

Figure 7 Bicoherence of the state $x_{1}$ of the fractional-order system.

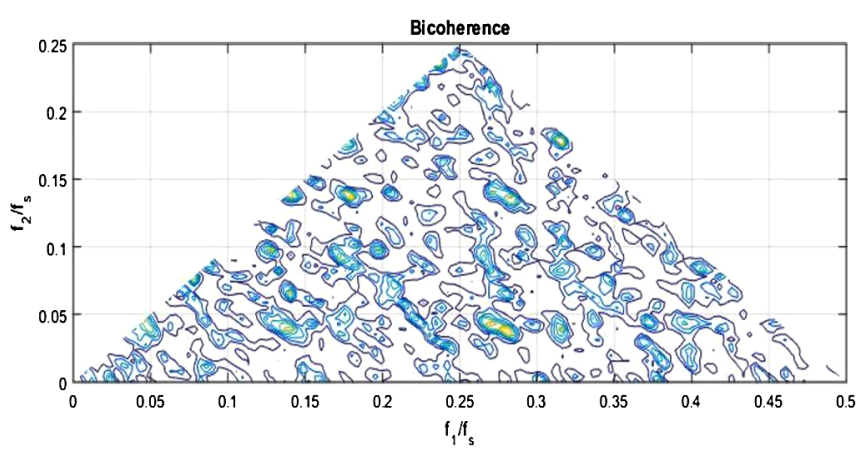

Figure 8 Bicoherence of the state $x_{2}$ of the fractional-order system.

where $\omega_{n}$ is the radian frequency, and $A$ is the Fourier coefficients of the time series.

The normalized magnitude spectrum of the bispectrum known as the squared bicoherence is given by

$$
b\left(\omega_{1}, \omega_{2}\right)=\left|B\left(\omega_{1}, \omega_{2}\right)\right|^{2} / P\left(\omega_{1}\right) P\left(\omega_{2}\right) P\left(\omega_{1}+\omega_{2}\right),
$$

where $P\left(\omega_{1}\right)$ and $P\left(\omega_{2}\right)$ are the power spectrums at $f_{1}$ and $f_{2}$.

The bicoherence of the states of the fractional-order induction motor system (6) is shown in Figures 7-9. 


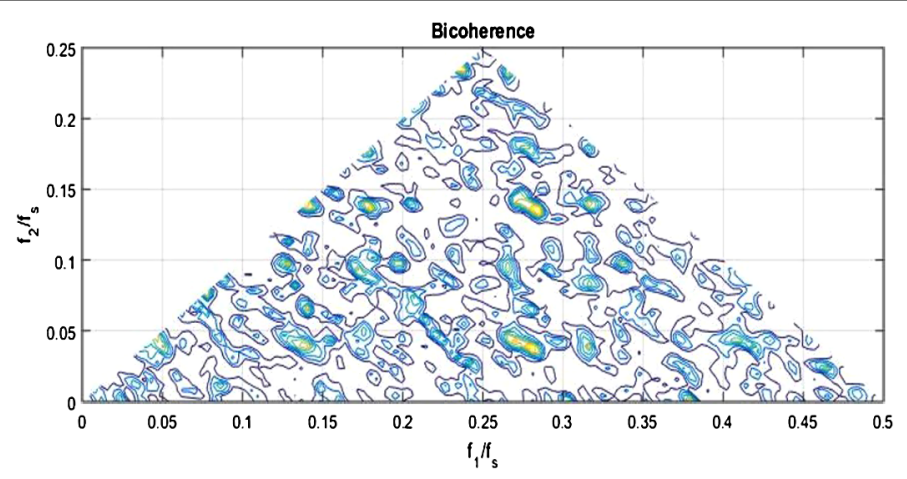

Figure 9 Bicoherence of the state $x_{3}$ of the fractional-order system.

\section{Stability analysis of FOIM system}

Commensurate Order: For a commensurate FOIM system of order $q$, the system is stable and exhibits chaotic oscillations if $\left|\arg \left(\operatorname{eig}\left(J_{E}\right)\right)\right|=\left|\arg \left(\lambda_{i}\right)\right|>\frac{q \pi}{2}$, where $J_{E}$ is the Jacobian matrix at the equilibrium $E$, and $\lambda_{i}$ are the eigenvalues of the FOIM system, where $i=$ $1,2,3,4$. As seen from the FOIM system, the eigenvalues should remain in the unstable region, and the necessary condition for the FOIM system to be stable is $q>\frac{2}{\pi} \tan ^{-1}\left(\frac{|\operatorname{Im} \lambda|}{\operatorname{Re} \lambda}\right)$. As the eigenvalues of the system are $\lambda_{1,2}=1.303 \pm 29.080 i, \lambda_{3}=-18.26$, and $\lambda_{4}=-13.82$, it is clearly seen that $\lambda_{1,2}$ is a complex pair of eigenvalues and remains in the unstable region contributing to the existence of chaotic oscillations.

Incommensurate Order: The necessary condition for the FOIM system to exhibit chaotic oscillations in the incommensurate case is $\frac{\pi}{2 M}-\min _{i}(|\arg (\lambda i)|)>0$, where $M$ is the LCM of the fractional orders. If $q_{x}=0.9, q_{y}=0.9, q_{z}=0.8, q_{w}=0.8$, then $M=10$. The characteristic equation of the system evaluated at the equilibrium is $\operatorname{det}\left(\operatorname{diag}\left[\lambda^{M q_{x}}, \lambda^{M q_{y}}, \lambda^{M q_{z}}, \lambda^{M q_{w}}\right]-J_{E}\right)=0$, and by substituting the values of $M$ and the fractional orders, $\operatorname{det}\left(\operatorname{diag}\left[\lambda^{9}, \lambda^{9}, \lambda^{8}, \lambda^{8}\right]-J_{E}\right)=0$, the characteristic equation is $\lambda^{26}+15.22 \lambda^{25}+$ $33.57 \lambda^{18}+62.85 \lambda^{17}+189.29 \lambda^{16}+\lambda^{12}+19.34 \lambda^{11}+857.47 \lambda^{10}+16,699 \lambda^{9}+447.95 \lambda^{8}+\lambda^{4}+$ $29.46 \lambda^{3}+1,016 \lambda^{2}+26,515 \lambda+213,680$. The approximated solution of the characteristic equation is $\lambda_{26}=-1.3159$, its argument is zero, which is the minimum argument, and hence the necessary stability condition becomes $\frac{\pi}{20}-0>0$, that is, $0.1571>0$. Hence, the FOIM system is stable, and chaos exists in the incommensurate system.

\section{Chaos suppression of the fractional-order system using adaptive sliding mode control (ASMC)}

The control goal of this paper is to design a suitable adaptive sliding mode controller for suppression of chaotic oscillations in the fractional-order induction motor (6). For deriving the robust ASMC controller for system (6), let us redefine the fractional-order system with a sliding mode controller $u(t)$ :

$$
\left\{\begin{array}{l}
{ }_{a}^{c} D_{t}^{q_{1}} x_{1}=-c_{1} x_{1}+c_{2} x_{4}-\frac{k c_{1}}{u_{2}^{0}} x_{2} x_{4}+u_{1}(t), \\
{ }_{a}^{c} D_{t}^{q_{2}} x_{2}=-c_{1} x_{2}+c_{2} u_{2}^{0}+\frac{k c_{1}}{u_{2}^{0}} x_{1} x_{4}+u_{2}(t), \\
{ }_{a}^{c} D_{t}^{q_{3}} x_{3}=-c_{3} x_{3}-c_{4}\left[c_{5}\left(x_{2} x_{4}-x_{1} u_{2}^{0}\right)-T_{L}-\frac{c_{3}}{c_{4}} w_{\mathrm{ref}}\right]+u_{3}(t), \\
{ }_{a}^{c} D_{t}^{q_{4}} x_{4}=\left(k_{i}-k_{p} c_{3}\right) x_{3}-k_{p} c_{4}\left[c_{5}\left(x_{2} x_{4}-x_{1} u_{2}^{0}\right)-T_{L}-\frac{c_{3}}{c_{4}} w_{\mathrm{ref}}\right]+u_{4}(t) .
\end{array}\right.
$$


Let us define the integral sliding mode surface as

$$
\left\{\begin{array}{l}
s_{1}=x_{1}+k_{1} \int_{0}^{t} x_{1}(\tau) d \tau, \\
s_{2}=x_{2}+k_{2} \int_{0}^{t} x_{2}(\tau) d \tau, \\
s_{3}=x_{3}+k_{3} \int_{0}^{t} x_{3}(\tau) d \tau, \\
s_{4}=x_{4}+k_{4} \int_{0}^{t} x_{4}(\tau) d \tau .
\end{array}\right.
$$

The parameter estimation error for the variable uncertain load $T_{L}$ is defined as

$$
e_{T_{L}}=\hat{T}_{L}-T_{L}
$$

The fractional derivative of the estimation error is

$$
D^{q} e_{T_{L}}=D^{q} \hat{T}_{L}
$$

The fractional derivatives of the sliding surface (12) are

$$
\left\{\begin{array}{l}
D^{q_{1}} s_{1}=D^{q_{1}} x_{1}+k_{1} x_{1}, \\
D^{q_{2}} s_{2}=D^{q_{2}} x_{2}+k_{2} x_{2}, \\
D^{q_{3}} s_{3}=D^{q_{3}} x_{3}+k_{3} x_{3}, \\
D^{q_{4}} s_{4}=D^{q_{4}} x_{4}+k_{4} x_{4} .
\end{array}\right.
$$

Let us consider the following Lyapunov function:

$$
V=\frac{1}{2}\left[s_{1}^{2}+s_{2}^{2}+s_{3}^{2}+s_{4}^{2}+e_{T_{L}}^{2}\right]
$$

The first derivative of the Lyapunov candidate function is

$$
\dot{V}=s_{1} \dot{s}_{1}+s_{2} \dot{s}_{2}+s_{3} \dot{s}_{3}+s_{4} \dot{s}_{4}+e_{T_{L}} \dot{e}_{T_{L}}
$$

By the definition of fractional calculus $[45,46]$ we obtain

$$
\dot{x}(t)=D_{t}^{1-q} \cdot D_{t}^{q} x(t) .
$$

Applying (18) in (17), we have

$$
\dot{V}=s_{1} D_{t}^{1-q} \cdot D_{t}^{q} s_{1}+s_{2} D_{t}^{1-q} \cdot D_{t}^{q} s_{2}+s_{3} D_{t}^{1-q} \cdot D_{t}^{q} s_{3}+s_{4} D_{t}^{1-q} \cdot D_{t}^{q} s_{4}+e_{T_{L}} D_{t}^{1-q} \cdot D_{t}^{q} e_{T_{L}}
$$

Thus, it is clear that stability calculations with (22) are very difficult. So, we use modified Lyapunov stability theory as given in $[47,54,55]$.

Let $e(t)$ be a continuous and differentiable function.

As proved in [47], for any time instant $t \geq t_{0}$, we have

$$
\frac{1}{2} D_{t}^{q} e^{2}(t) \leq e(t) \times D_{t}^{q} e(t) \quad \forall q \in(0,1)
$$


Using (23) in (19), we have

$$
\begin{aligned}
\dot{V}= & s_{1}\left[D^{q_{1}} x_{1}+k_{1} x_{1}\right]+s_{2}\left[D^{q_{2}} x_{2}+k_{2} x_{2}\right]+s_{3}\left[D^{q_{3}} x_{3}+k_{3} x_{3}\right] \\
& +s_{4}\left[D^{q_{4}} x_{4}+k_{4} x_{4}\right]+e_{T_{L}} D^{q} \hat{T}_{L} .
\end{aligned}
$$

Applying (14) in (24), we have

$$
\begin{aligned}
\dot{V}= & s_{1}\left[-c_{1} x_{1}+c_{2} x_{4}-\frac{k c_{1}}{u_{2}^{0}} x_{2} x_{4}+u_{1}(t)+k_{1} x_{1}\right] \\
& +s_{2}\left[-c_{1} x_{2}+c_{2} u_{2}^{0}+\frac{k c_{1}}{u_{2}^{0}} x_{1} x_{4}+u_{2}(t)+k_{2} x_{2}\right] \\
& +s_{3}\left[-c_{3} x_{3}-c_{4} c_{5}\left(x_{2} x_{4}-x_{1} u_{2}^{0}\right)+c_{4} \hat{T}_{L}+c_{3} W_{\mathrm{ref}}+u_{3}(t)+k_{3} x_{3}\right] \\
& +s_{4}\left[\begin{array}{l}
\left.\left(k_{i}-k_{p} c_{3}\right) x_{3}-k_{p} c_{4} c_{5}\left(x_{2} x_{4}-x_{1} u_{2}^{0}\right)+k_{p} c_{4} \hat{T}_{L}\right]+e_{T_{L}} D^{q} \hat{T}_{L} . \\
+k_{p} c_{3} W_{\mathrm{ref}}+u_{4}(t)+k_{4} x_{4}
\end{array}\right]
\end{aligned}
$$

Let us define the adaptive controllers as

$$
\left\{\begin{aligned}
u_{1}(t)= & c_{1} x_{1}-c_{2} x_{4}+\frac{k c_{1}}{u_{2}^{0}} x_{2} x_{4}-k_{1} x_{1}-\eta_{1} \operatorname{sgn}\left(s_{1}\right)-\rho_{1} s_{1}, \\
u_{2}(t)= & c_{1} x_{2}-c_{2} u_{2}^{0}-\frac{k c_{1}}{u_{2}^{0}} x_{1} x_{4}-k_{2} x_{2}-\eta_{2} \operatorname{sgn}\left(s_{2}\right)-\rho_{2} s_{2}, \\
u_{3}(t)= & c_{3} x_{3}+c_{4} c_{5}\left(x_{2} x_{4}-x_{1} u_{2}^{0}\right)-c_{4} \hat{T}_{L}-c_{3} W_{\text {ref }} \\
& -k_{3} x_{3}-\eta_{3} \operatorname{sgn}\left(s_{3}\right)-\rho_{3} s_{3}, \\
u_{4}(t)= & -\left(k_{i}-k_{p} c_{3}\right) x_{3}+k_{p} c_{4} c_{5}\left(x_{2} x_{4}-x_{1} u_{2}^{0}\right)-k_{p} c_{4} \hat{T}_{L} \\
& -k_{p} c_{3} W_{\text {ref }}-k_{4} x_{4}-\eta_{4} \operatorname{sgn}\left(s_{4}\right)-\rho_{4} s_{4} .
\end{aligned}\right.
$$

Let us define the parameter estimation law as

$$
D^{q} \hat{T}_{L}=c_{4}\left[s_{3}+k_{p} s_{4}\right]
$$

By applying the parameter update law (27) and adaptive controllers (26) in (25), we have

$$
\dot{V} \leq-\eta_{1}\left|s_{1}\right|-\eta_{2}\left|s_{2}\right|-\eta_{3}\left|s_{3}\right|-\eta_{4}\left|s_{4}\right|-\rho_{1} s_{1}^{2}-\rho_{2} s_{2}^{2}-\rho_{3} s_{3}^{2}-\rho_{4} s_{4}^{2}
$$

As $\rho_{i}$ and $\eta_{i}$ are positive for $i=1,2,3,4$, the Lyapunov first derivative (28) is a negative definite function. This establishes that the closed-loop control system is asymptotically stable for all initial conditions.

\section{Numerical simulations of ASMC}

The fractional-order induction motor (FOIM) given by equation (18) with the robust adaptive sliding mode controller (26) is implemented in LabVIEW for numerical analysis and validation.

The initial conditions are chosen as in (12), and the parameter values are chosen as in (13). The fractional orders of system (14) are chosen as in (7). The controller gains are taken to be $k_{1}=10, k_{2}=10, k_{3}=10, k_{4}=10$. 
The initial condition of the FOIM states are selected as in (8), and the initial condition for the uncertain load is selected as $T_{L}=2$, and the load to be estimated is $T_{L}=0.5$. The state trajectories of the controlled fractional-order induction chaotic system (18) are shown Figure 10, where the controller is switched at $t=10 \mathrm{~s}$. Figure 11 shows the parame-

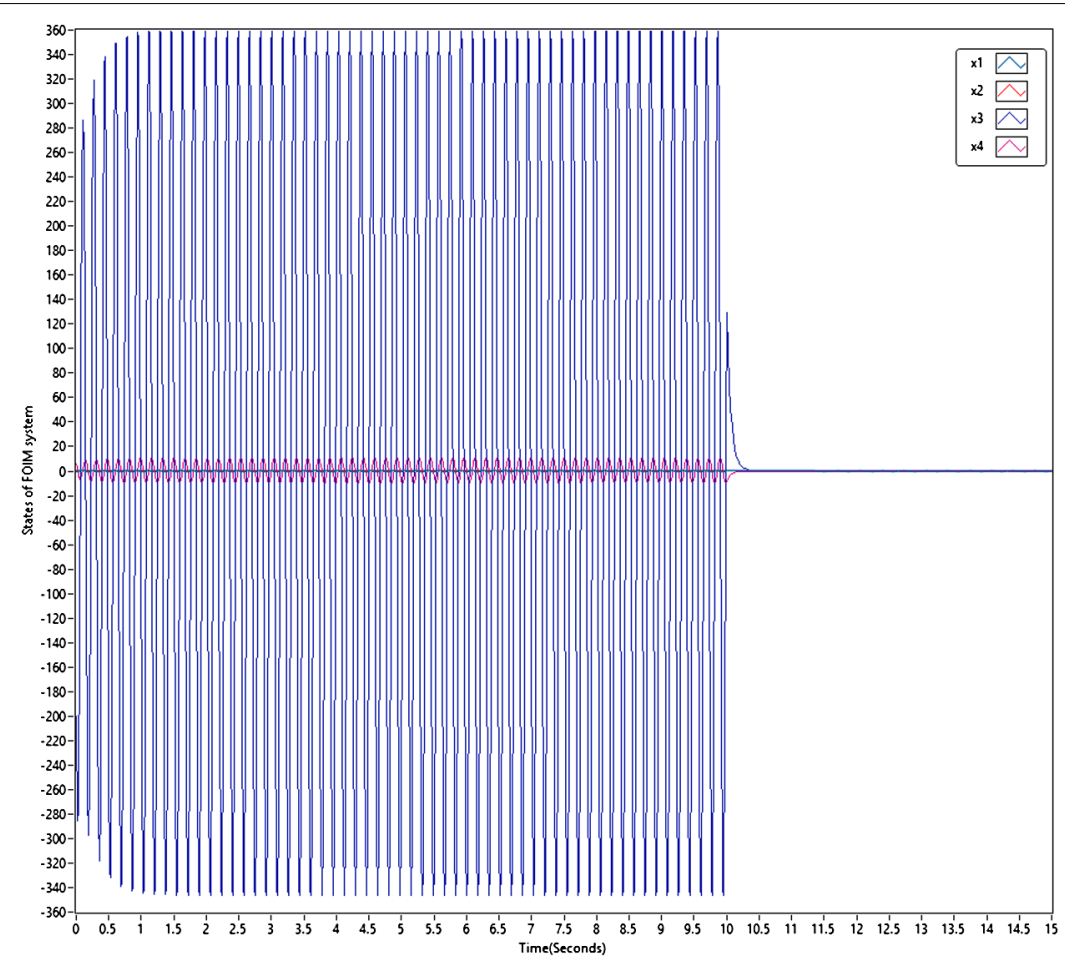

Figure 10 Fractional-order system states oscillations without and with controller ( $t=10 \mathrm{~s})$.

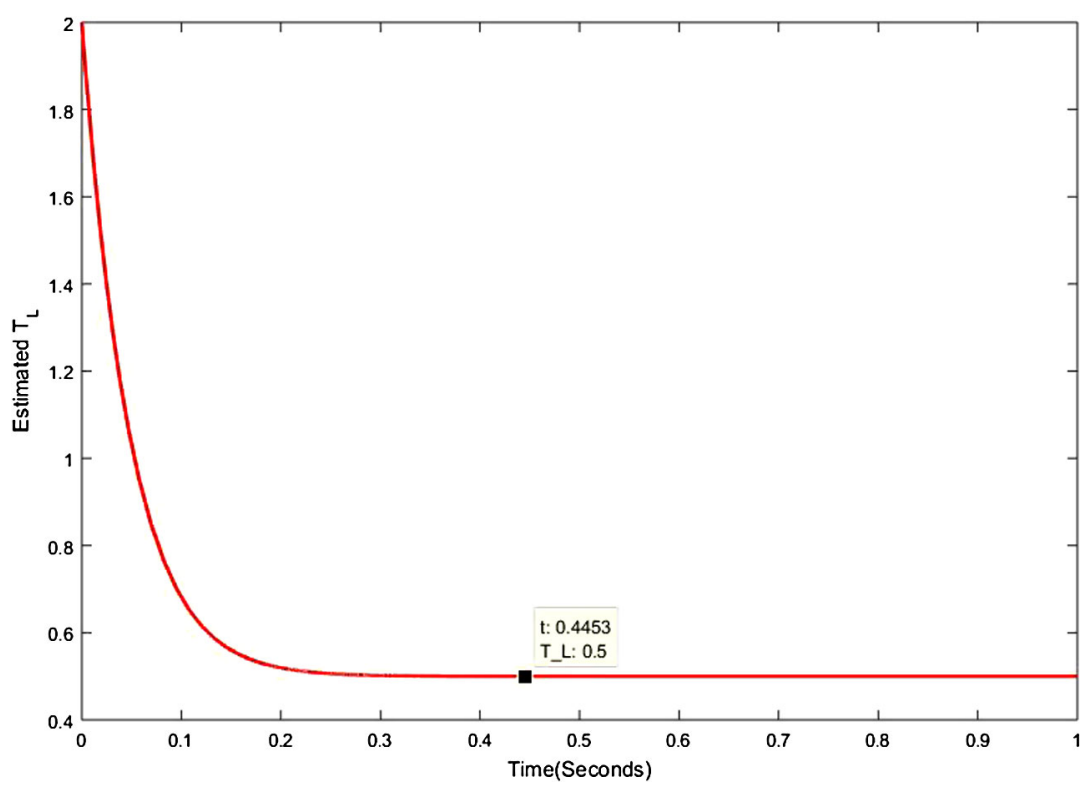

Figure 11 Estimated unknown load values with controller in action at $t=0.1 \mathrm{~s}$. 
ter estimate with controller in action from $t=0.1 \mathrm{~s}$. It can be clearly observed that the state trajectories converge to zero as soon as the controller is introduced, which clearly shows that the fractional-order system (5) is well controlled by the adaptive controller with the uncertainty in the Load Torque.

\section{Chaos suppression using genetically optimized fractional-order PID controllers}

Fractional-order PID controllers described by using fractional calculus are the most common and useful algorithms in control system engineering. In most cases, feedback loops are controlled using PID Algorithms, designed to correct error(s) between instant value(s) in a system and chosen set point values. Design of FOPID controller using Genetic Algorithms (GAs), which are a stochastic global search method that mimics the process of natural evolution. It is one of the methods used for optimization successfully applied in [59-61].

A genetic algorithm has to be initialized before the algorithm can proceed. The Initialization of the population size, variable bounds, and the evaluation objective functions are required to evaluate the best gain values of FOPID controller for the system. An objective function can created to find a FOPID controller that gives a minimal error. The error functions such as sum absolute error (SAE) are used as objective functions in this work.

Let us define the fractional-order PID controllers as

$$
u_{i}=K_{P} e_{i}+K_{I} \int_{0}^{t} e_{i} d \tau^{\beta}+K_{D} \frac{d^{\delta} e_{i}}{d t^{\delta}}, \quad i=x_{1}, x_{2}, x_{3}, x_{4}
$$

where $u_{i}$ is the fractional-order PID action control for $i=x_{1}, x_{2} ; x_{3} ; x_{4} \delta, \beta$ are the fractional-order differential and integral operators [44, 45], $e_{i}$ is the error signal, and $K_{P}, K_{I}, K_{D}$ are the proportional, integral, and derivative gains to suppress the nonlinearity in the fractional-order current-driven induction motor (FOIM).

MATLAB is used for numerical simulation with the following options:

Variable bound matrix of the proportional, integral, and derivative gains is $[-0.001$, $0.001]$, but for the states $\left(x_{3}, x_{4}\right)$, the values are multiplied by hundred and ten for the difference of variation range.

The population size is 100 . Generally, the greater the population size, the better is the final approximation, and the number of generations is 100. The selection function is Stochastic uniform. The crossover fraction is 0.8 . The mutation function is Gaussian. The stopping criterion is Error performance criterion. The length of the chromosome is 12 , decimal coding. The objective function is written based on the error performance criterion sum absolute error as

$$
\text { fitness }=\frac{1}{\sum\left(e_{i}\right)}
$$

where $e_{i}=\operatorname{abs}\left(e_{x 1}\right)+\operatorname{abs}\left(e_{x 2}\right)+\operatorname{abs}\left(e_{x 3}\right)+\operatorname{abs}\left(e_{X 4}\right)$.

Table 1 shows the FOPID gain values after running the GA solver from the optimization tool with the options cited before. We get the best solutions tracked over generations for 
Table 1 FOPID controller gain values optimized with GA

\begin{tabular}{lccl}
\hline FOPID controller & $\boldsymbol{K}_{\boldsymbol{P}}$ & $\boldsymbol{K}_{\boldsymbol{I}}$ & $\boldsymbol{K}_{\boldsymbol{D}}$ \\
\hline$u_{x_{1}}$ & 0.0023 & 0.0128 & 0.0076 \\
$u_{x_{2}}$ & -0.0028 & -0.0110 & 0.0052 \\
$u_{x_{3}}$ & 1.29 & 0.98 & 2.02 \\
$u_{x_{4}}$ & 0.065 & 0.106 & 0.045 \\
\hline
\end{tabular}

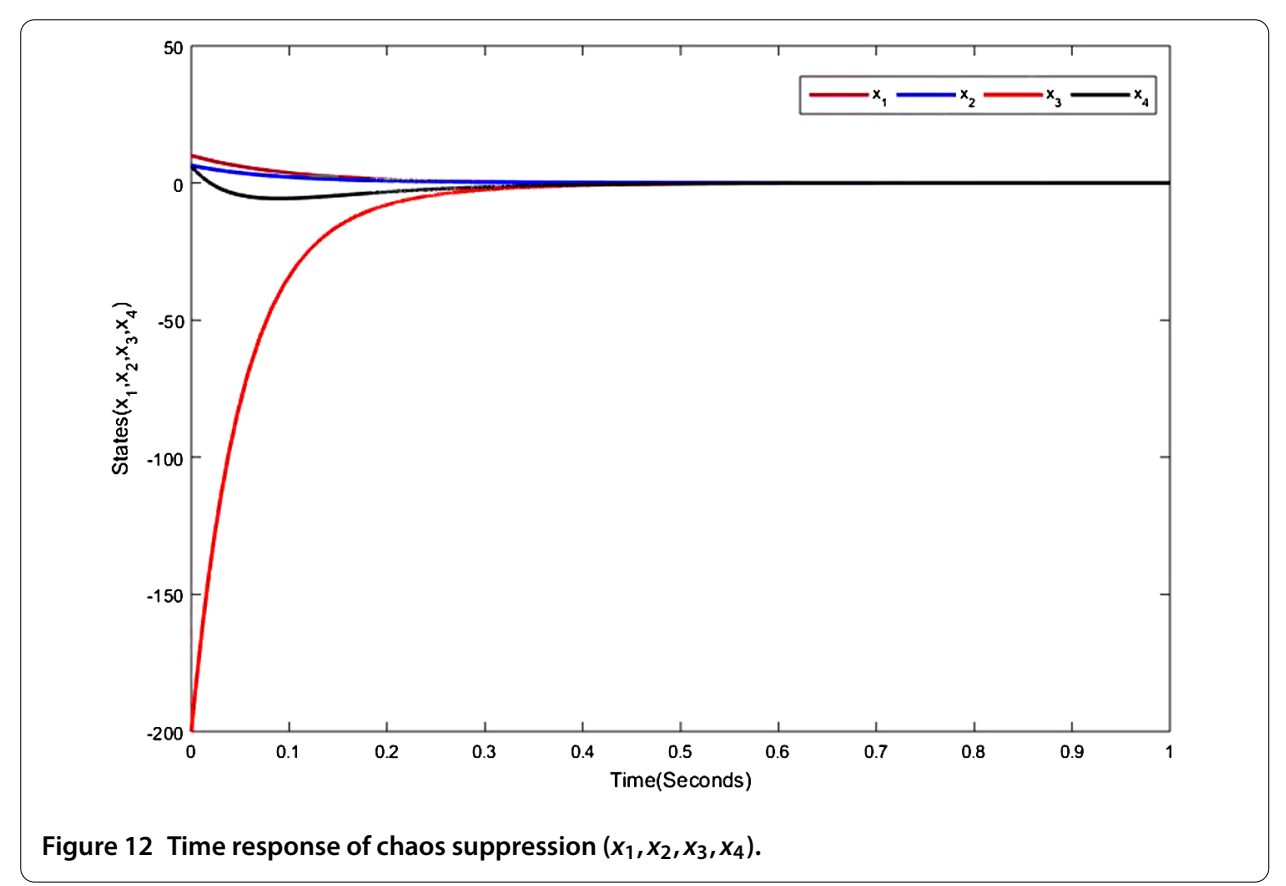

the complete chaos suppression of the FOIM system via fractional-order PID controllers using gains values genetically optimized, Figure 12 shows the time history of the FOIM states $\left(x_{1}, x_{2}, x_{3}, x_{4}\right)$, and Figure 13 shows the time response of fractional-order PID controllers $\left(u_{x_{1}}, u_{x_{2}}, u_{x_{3}}, u_{x_{4}}\right)$.

Many real dynamic systems are better characterized using a noninteger-order dynamic model based on fractional calculus or differentiation or integration of noninteger order. Therefore fractional-order PID controllers are the future of nonlinear control theory.

\section{FPGA implementation of the FOASMC}

In this section, we discuss the implementation of the FOIM and FOASMC models in FPGA [55] using the Xilinx (Vivado) System Generator toolbox in Simulink. First, we configure the available built-in blocks of the System Generator toolbox. The Add/Sub blocks are configured with zero latency and 32/16-bit fixed-point settings. The output of the block is configured to rounded quantization to reduce the bit latency. For the multiplier block, a latency of 3 is configured, and the remaining settings are as in Add/Sub block. Next, we have to design the fractional-order integrator, which is not a readily available block in the System Generator. Hence we implement the integrators using the mathematical relation discussed in (4) and (5) with the memory element required for configuring the fractional order with memory coefficients described by a combination of forward registers with $h=0.001$ and the initial conditions fed into the forward register. Figure 14 

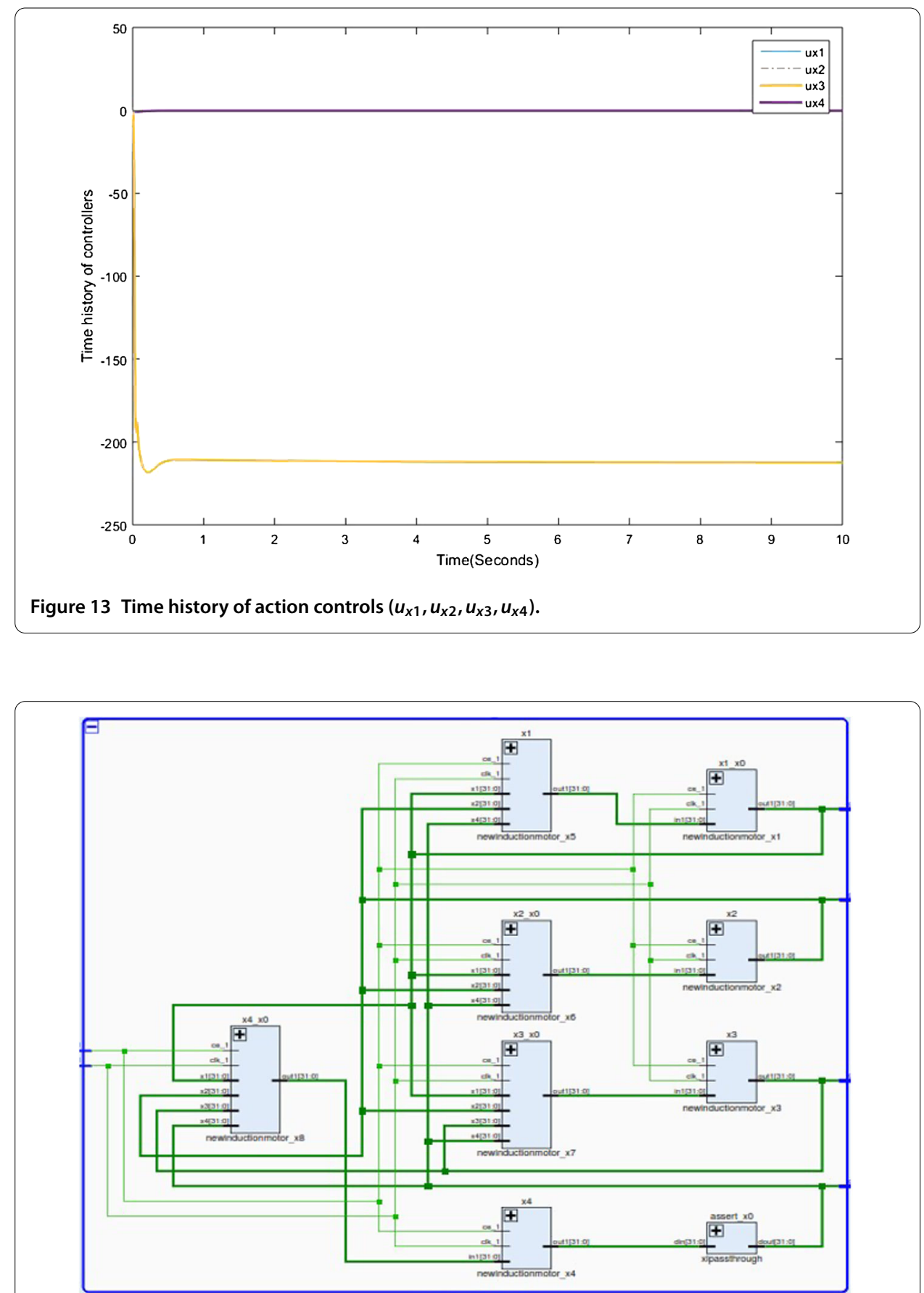

Figure 14 Xilinx RTL schematics of the FOIM system.

shows the Xilinx RTL schematics of the FOIM system implemented in Kintex 7 (Device = $7 \mathrm{k} 160 \mathrm{t}$, Package $=$ fbg484 S), and Figure 15 shows the Xilinx RTL Kintex 7 schematics of the FOASMC with fractional-order integrators. Figure 16 shows the parameter update laws for estimating the unknown load. Figure 17 shows the RTL shematics of sliding surfaces with the sliding reaching laws. Figure 18 shows the controlled states of the FOIM system using FOASMC controllers implemented using Xilinx System Generator. 


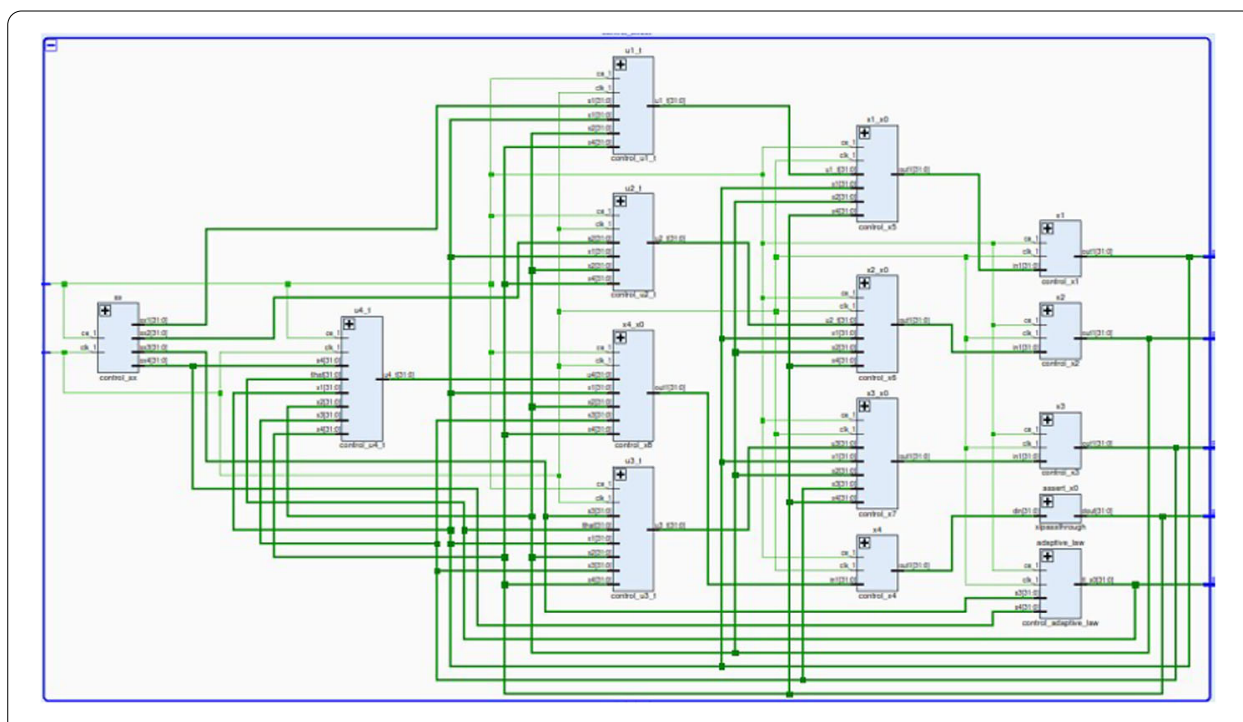

Figure 15 Xilinx RTL schematics of the ASMC.

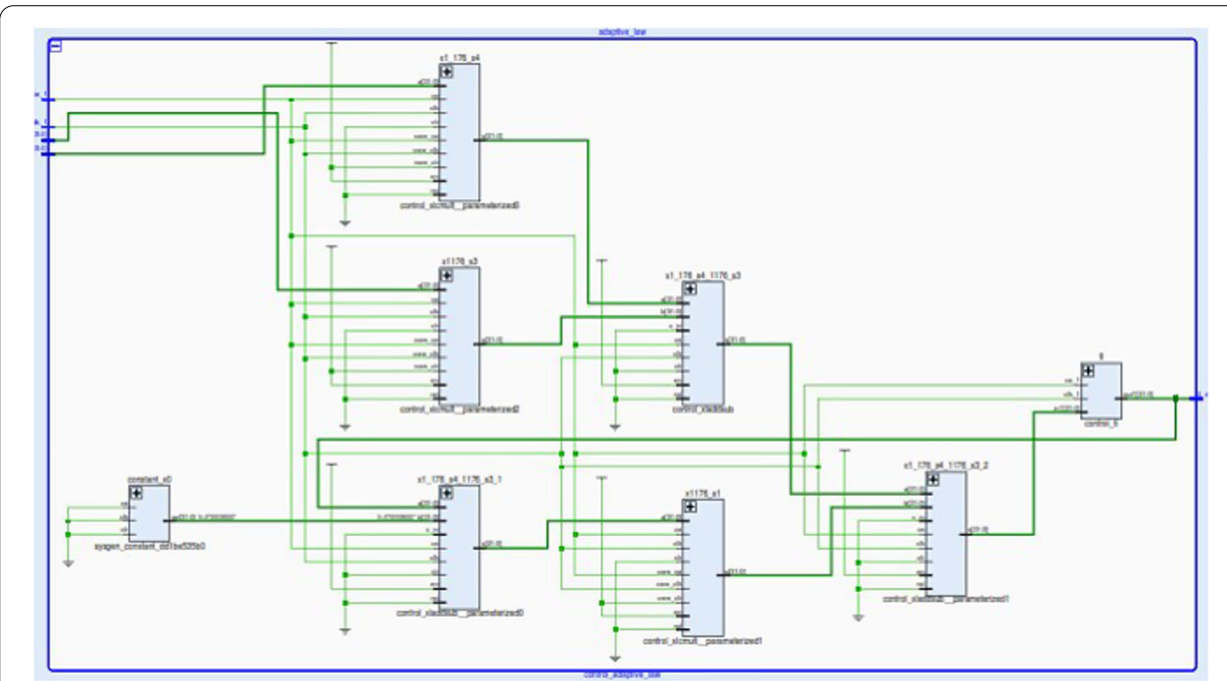

Figure 16 Xilinx RTL schematics of the parameter update law.

\section{Conclusion}

This paper investigates the control of dimensionless nonautonomous fractional-order uncertain load torque model of an induction motor via an adaptive control technique. First, the dimensionless fractional-order model of the induction motor is derived from the integer-order model discussed in the literature using the Caputo-Riemann-Liouville fractional derivatives. To study the effects of variation of parameters on the fractional-order system performance, we have investigated the bifurcation analysis of a fractional-order system with respect to the load torque. It is also shown that the fractional-order induction motor is not only prone to instability due to Hopf bifurcation, but it also exhibits limit cycles and chaos due to bifurcation other than Hopf bifurcation, which is shown by the bicoherence plots. This bispectrum analysis helps us in choosing the appropriate param- 


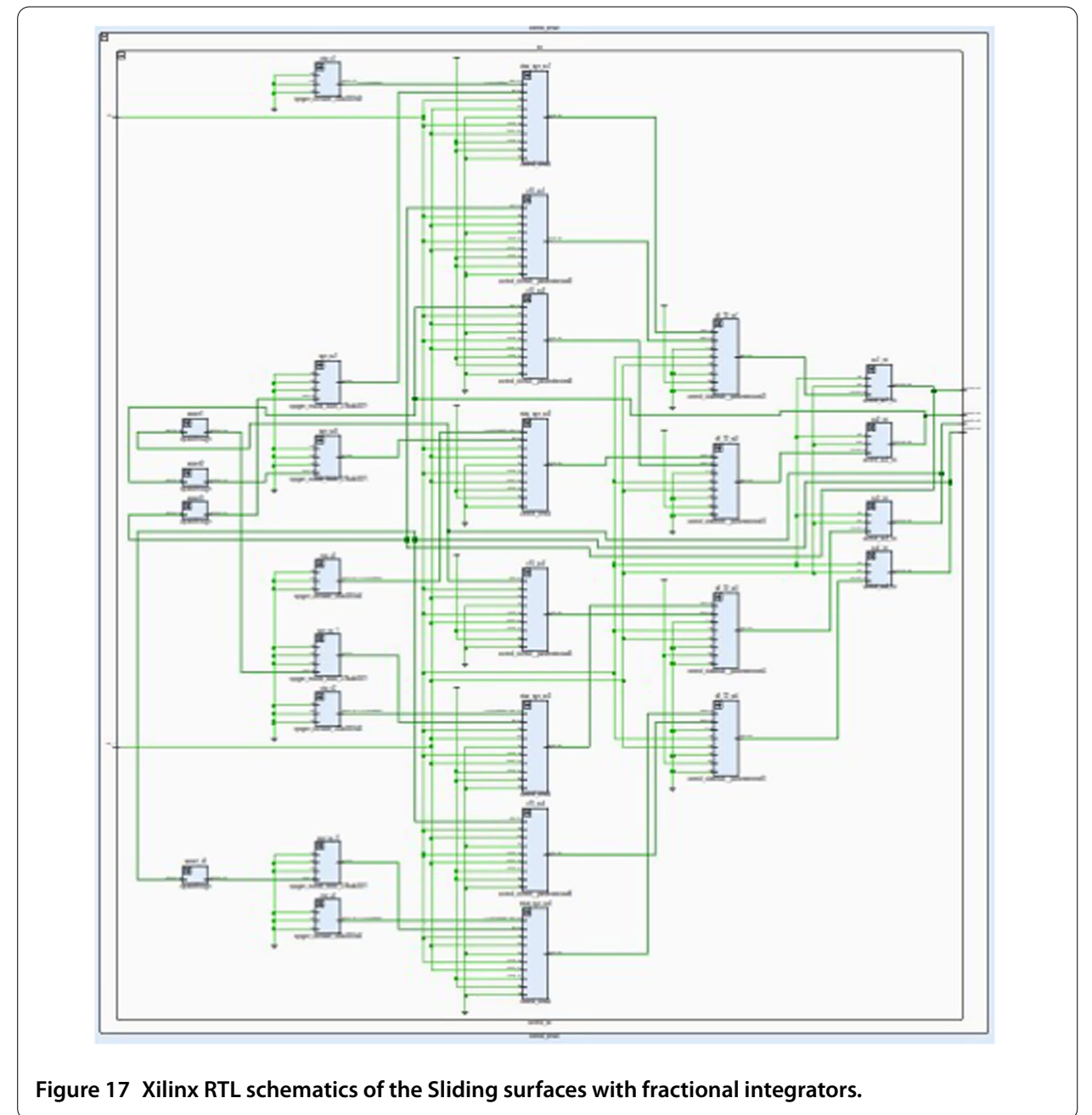

eters for the proper work of the motor. As understood from the dynamic analysis of the fractional-order system, it is seen that chaos oscillations are exhibited for a particular selection of parameters. To suppress such chaotic oscillations, we have derived an adaptive control technique assuming that the operating load torque parameters of the fractionalorder induction motor system are unknown. Numerical results are shown to illustrate the adaptive controller derived in this work.

\section{Competing interests}

The authors declare that they have no competing interests.

Authors' contributions

All authors read and approved the final manuscript.

\section{Author details}

${ }^{1}$ Centre for Non-Linear Dynamics, Defense University, Bishoftu, Ethiopia. ${ }^{2}$ Center for Nonlinear Dynamics, Ethiopia Technology Faculty, Ferhat Abbes University, Setif, Algeria.

\section{Publisher's Note}

Springer Nature remains neutral with regard to jurisdictional claims in published maps and institutional affiliations.

Received: 22 May 2017 Accepted: 27 August 2017 Published online: 07 September 2017 


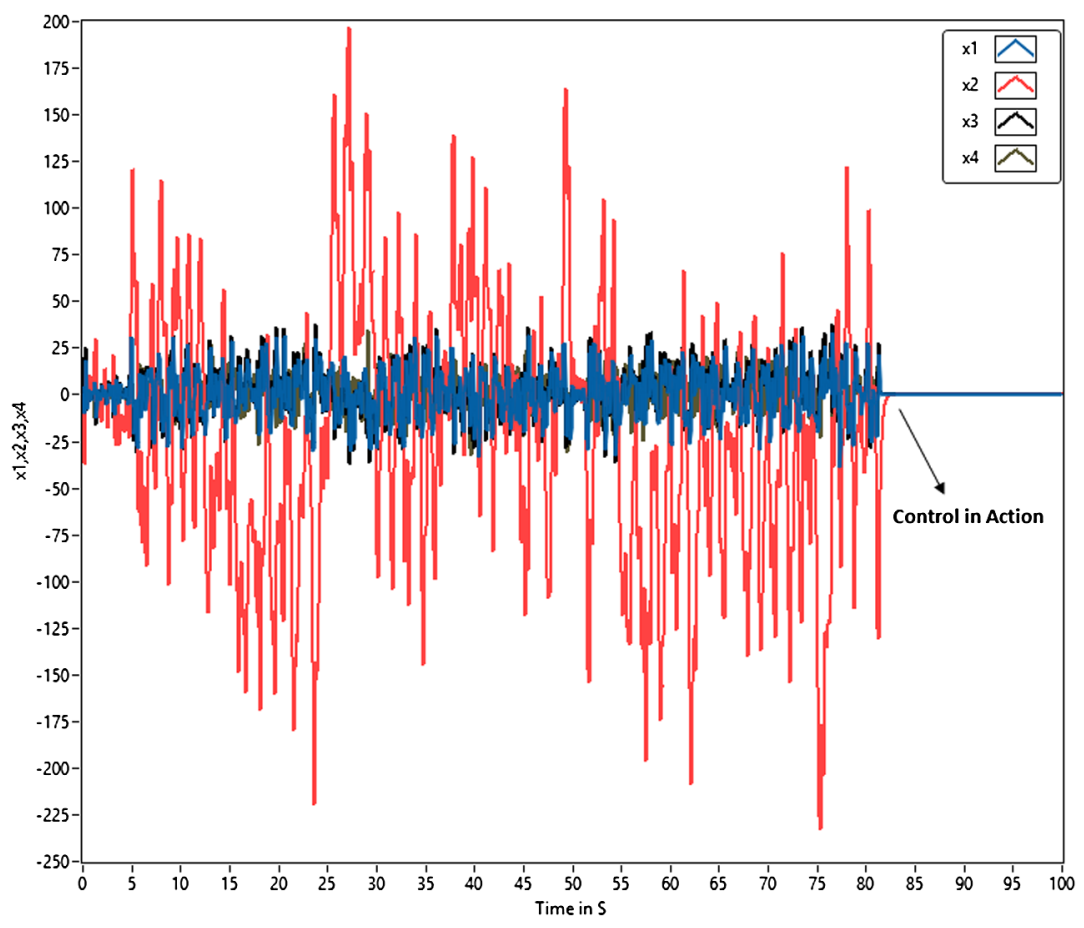

Figure 18 FPGA implemented ASMC controller in action at $t=85 \mathrm{~s}$.

\section{References}

1. Machowski, J, Bialek, JW, Bumby, JR: Power System Dynamics: Stability and Control. Wiley, New Jersey (2008)

2. Solovyeva, E: Mathematical Models and Stability Analysis of Induction Motors Under Sudden Changes of Load. Jyväskylä Studies in Computing, vol. 182. University of Jyväskylä, Jyväskylä (2013)

3. Chang, YH, Wu, Cl, Lin, HW, Chen, HC, Chang, CW: Fractional order integral sliding mode flux observer for direct field oriented induction machines. Int. J. Innov. Comput. Inf. Control 8(7A), 4851-4868 (2012)

4. Tavazoei, MS, Haeri, M: A note on the stability of fractional order systems. Math. Comput. Simul. 70(5), 1566-1579 (2009)

5. Cao, YG, Li, Y, Ren, W, Chen, YQ: Distributed coordination of networked fractional order systems. IEEE Trans. Syst. Man Cybern., Part B, Cybern. 40(2), 362-370 (2010)

6. Podlubny, I: Fractional order systems and $\mathrm{PI}^{\lambda} \mathrm{D}^{\mu}$ controllers. IEEE Trans. Autom. Control 44(1), 208-213 (1999)

7. Azar, AT, Vaidyanathan, S: Chaos Modeling and Control Systems Design. Springer, Berlin (2015)

8. Azar, AT, Vaidyanathan, S: Advances in Chaos Theory and Intelligent Control. Springer, Berlin (2016)

9. Vaidyanathan, S, Volos, C: Advances and Applications in Nonlinear Control Systems. Springer, Berlin (2016)

10. Vaidyanathan, S, Volos, C: Advances and Applications in Chaotic Systems. Springer, Berlin (2016)

11. Nategh, M, Baleanu, D, Valinejad, MR: On a discrete chaos induction via an aperiodic kicks pattern. J. Comput. Nonlinear Dyn. 12(4), 041008 (2017)

12. Yang, J, Zhao, L: Bifurcation analysis and chaos control of the modified Chua's circuit system. Chaos Solitons Fractals 77, 332-339 (2015)

13. Sundarapandian, V, Karthikeyan, R: Hybrid synchronization of hyperchaotic Lorenz and hyperchaotic Chen systems via active control. J. Eng. Appl. Sci. 7(3), 254-264 (2012)

14. Karthikeyan, R, Sundarapandian, $\mathrm{V}$ : Hybrid chaos synchronization of four-scroll systems via active control. J. Electr. Eng. 65(2), 97-103 (2014)

15. Vaidyanathan, S, Azar, AT, Rajagopal, K, Alexander, P: Design and SPICE implementation of a 12-term novel hyperchaotic system and its synchronisation via active control. Int. J. Model. Identif. Control 23(3), 267-277 (2015)

16. Vaidyanathan, S: Active control design for the anti-synchronization of Lotka-Volterra biological systems with four competitive species. Int. J. PharmTech Res. 8(7), 58-70 (2015)

17. Pehlivan, I, Moroz, IM, Vaidyanathan, S: Analysis, synchronization and circuit design of a novel butterfly attractor. J. Sound Vib. 333(20), 5077-5096 (2014)

18. Vaidyanathan, S, Rajagopal, K: Analysis, control, synchronization and LabVIEW implementation of a seven-term novel chaotic system. Int. J. Control Theory Appl. 9(1), 151-174 (2016)

19. Vaidyanathan, S: Synchronization of Tokamak systems with symmetric and magnetically confined plasma via adaptive control. Int. J. ChemTech Res. 8(6), 818-827 (2015)

20. Vaidyanathan, S: Anti-synchronization of Rikitake two-disk dynamo chaotic systems via adaptive control method. Int. J. ChemTech Res. 8(9), 393-405 (2015)

21. Vaidyanathan, S, Rajagopal, K: Adaptive control, synchronization and LabVIEW implementation of Rucklidge chaotic system for nonlinear double convection. Int. J. Control Theory Appl. 9(1), 175-197 (2016) 
22. Yau, HT: Design of adaptive sliding mode controller for chaos synchronization with uncertainties. Chaos Solitons Fractals 22(2), 341-347 (2004)

23. Vaidyanathan, S, Boulkroune, A: A novel hyperchaotic system with two quadratic nonlinearities, its analysis and synchronization via integral sliding mode control. Int. J. Control Theory Appl. 9(1), 321-337 (2016)

24. Vaidyanathan, S, Sampath, S, Azar, AT: Global chaos synchronization of identical chaotic systems via novel sliding mode control method and its application to Zhu system. Int. J. Model. Identif. Control 23(1), 92-100 (2015)

25. Sampath, S, Vaidyanathan, S: Hybrid synchronization of identical chaotic systems via novel sliding control method with application to Sampath four-scroll chaotic system. Int. J. Control Theory Appl. 9(1), 221-235 (2016)

26. Wang, C, Ge, SS: Adaptive synchronization of uncertain chaotic systems via backstepping design. Chaos Solitons Fractals 12(7), 1199-1206 (2001)

27. Vaidyanathan, S: A novel hyperchaotic hyperjerk system with two nonlinearities, its analysis, adaptive control and synchronization via backstepping control method. Int. J. Control Theory Appl. 9(1), 257-278 (2016)

28. Vaidyanathan, S, Rasappan, S: Global chaos synchronization of $n$-scroll Chua circuit and Lur'e system using backstepping control design with recursive feedback. Arab. J. Sci. Eng. 39(4), 3351-3364 (2014)

29. Senouci, A, Boukabou, A: Fuzzy modeling, stabilization and synchronization of multi-scroll chaotic systems. Optik 127(13), 5351-5358 (2016)

30. Vaidyanathan, S, Azar, AT: Takagi-Sugeno fuzzy logic controller for Liu-Chen four-scroll chaotic system. Int. J. Intell. Eng. Inform. 4(2), 135-150 (2016)

31. Revel, G, Leon, AE, Alonso, DM, Moiola, JL: Multi-parameter bifurcation analysis of subsynchronous interactions in DFIG-based wind farms. Electr. Power Syst. Res. 140, 643-652 (2016)

32. Zarei, A, Tavakoli, S: Hopf bifurcation analysis and ultimate bound estimation of a new 4-D quadratic autonomous hyper-chaotic system. Appl. Math. Comput. 291, 323-339 (2016)

33. Kuznetsov, YA: Elements of Applied Bifurcation Theory. Springer, Berlin (1995)

34. Jabli, N, Khammari, H, Mimouni, MF, Dhifaoui, R: Bifurcation and chaos phenomena appearing in induction motor under variation of PI controller parameters. WSEAS Trans. Syst. 9(7), 784-793 (2010)

35. Sundarapandian, $V$, Pehlivan, I: Analysis, control, synchronization and circuit design of a novel chaotic system. Math Comput. Model. 55(7-8), 1904-1915 (2012)

36. Li, Y, Chen, Y, Podlubny, I: Stability of fractional-order nonlinear dynamic systems: Lyapunov direct method and generalized Mittag-Leffler stability. Comput. Math. Appl. 59(5), 1810-1821 (2010)

37. Gallegos, JA, Duarte-Mermoud, MA: On the Lyapunov theory for fractional order systems. Appl. Math. Comput. 287, 161-170 (2016)

38. Tavazoei, MS, Haeri, M: Chaos control via a simple fractional order controller. Phys. Lett. A 372, 798-807 (2008)

39. Konishi, K, Kokame, H, Hara, N: Delayed feedback control based on the act-and-wait concept. Nonlinear Dyn. 63, 513-519(2011)

40. Jin, Y, Chen, YQ, Xue, D: Time-constant robust analysis of a fractional order [proportional derivative] controller. IET Control Theory Appl. 5(1), 164-172 (2011)

41. Vaidyanathan, S, Rajagopal, K, Volos, C, Kyprianidis, IM, Stouboulos, IN: Analysis, adaptive control and synchronization of a seven-term novel 3-D chaotic system with three quadratic nonlinearities and its digital implementation in LabVIEW. J. Eng. Sci. Technol. Rev. 8(2), 130-141 (2015)

42. Chen, D, Shi,, , Ma, X: Control and synchronization of chaos in an induction motor system. Int. J. Innov. Comput. Inf. Control 8(10B), 7237-7248 (2012)

43. Li, H, Liao, X, Luo, M: A novel non-equilibrium fractional order chaotic system and its complete synchronization by circuit implementation. Nonlinear Dyn. 68(1), 137-149 (2012)

44. Petras, I: A note on the fractional order Chua's system. Chaos Solitons Fractals 38(1), 140-147 (2008)

45. Katugampola, UN: A new approach to generalized fractional derivatives. Bull. Math. Anal. Appl. 6(4), 1-15 (2014)

46. Herzallah, MAE: Notes on some fractional calculus operators and their properties. J. Fract. Calc. Appl. 5(19), 1-10 (2014)

47. Rajagopal, K, Vaidyanathan, S, Karthikeyan, A, Duraisamy, P: Dynamic analysis and chaos suppression in a fractional order brushless DC motor. Electr. Eng. (2016). doi:10.1007/s00202-016-0444-8

48. Jafari, S, Sprott, JC: Simple chaotic flows with a line equilibrium. Chaos Solitons Fractals 57, 79-84 (2013)

49. Jafari, S, Sprott, JC, Golpayegani, SMRH: Elementary quadratic chaotic flows with no equilibria. Phys. Lett. A 377(9), 699-702 (2013)

50. Pham, VT, Volos, C, Jafari, S, Wang, X, Vaidyanathan, S: Hidden hyperchaotic attractor in a novel simple memristive neural network. Optoelectron. Adv. Mater., Rapid Commun. 8(11-12), 1157-1163 (2014)

51. Pham, VT, Volos, C, Jafari, S, Wei, Z, Wang, X: Constructing a novel no-equilibrium chaotic system. Int. J. Bifurc. Chaos Appl. Sci. Eng. 24(5), Article ID 1450073 (2014)

52. Jafari, S, Sprott, JC, Nazarimehr, F: Recent new examples of hidden attractors. Eur. Phys. J. Spec. Top. 224(8), 1469-1476 (2015)

53. Sprott, JC, Jafari, S, Pham, VT, Hosseini, ZS: A chaotic system with a single unstable node. Phys. Lett. A 379(36), 2030-2036 (2015)

54. Rajagopal, K, Laarem, G, Karthikeyan, A, Srinivasan, A, Adam, G: Fractional order memristor no equilibrium chaotic system with its adaptive sliding mode synchronization and genetically optimized fractional order PID synchronization. Complexity 2017, Article ID 1892618 (2017)

55. Rajagopal, K, Karthikeyan, A, Srinivasan, A: FPGA implementation of novel fractional order chaotic system with two equilibriums and no equilibrium and its adaptive sliding mode synchronization. Nonlinear Dyn. 87(4), 2281-2304 (2017)

56. Baleanua, D, Wu, G, Zeng, S: Chaos analysis and asymptotic stability of generalized Caputo fractional differential equations. Chaos Solitons Fractals (2017). doi:10.1016/j.chaos.2017.02.007

57. Jajarmi, A, Hajipour, M, Baleanu, D: New aspects of the adaptive synchronization and hyperchaos suppression of a financial model. Chaos Solitons Fractals 99, 285-296 (2017)

58. Astrom, KJ, Hagglund, T: PID Controllers: Theory, Design and Tuning. Research Triangle Park, North Carolina (1995)

59. Goldberg, DE: Genetic Algorithms in Search, Optimization and Machine Learning. Addison-Wesley, Reading (1989) 
60. Wang, Q, Spronck, P, Tracht, R: An overview of genetic algorithms applied to control engineering problems. In: Proceedings of the Second International Conference on Machine Learning and Cybernetics, Xi'an, 3-5 Nov. 2003 (2003). doi:10.1109/ICMLC.2003.1259761

61. Chen, Z, Yuan, X, Ji, B, Wang, P, Tian, H: Design of a fractional order PID controller for hydraulic turbine regulating system using chaotic non-dominated sorting genetic algorithm II. Energy Convers. Manag. 84, 390-404 (2014)

62. Pezeshki, C: Bispectral analysis of systems possessing chaotic motions. J. Sound Vib. 137(3), 357-368 (1990)

63. Chandran, V, Elgar, S, Pezeshki, C: Bispectral and trispectral characterization of transition to chaos in the Duffing oscillator. Int. J. Bifurc. Chaos Appl. Sci. Eng. 3(3), 551-557 (1993)

\section{Submit your manuscript to a SpringerOpen ${ }^{\circ}$} journal and benefit from:

- Convenient online submission

- Rigorous peer review

- Open access: articles freely available online

- High visibility within the field

- Retaining the copyright to your article

Submit your next manuscript at $\gg$ springeropen.com 